\title{
Yam physic-chemical parameters assessment and its bread sensory attributes for corporate agribusiness boosting
}

\begin{abstract}
A research work entitled: "Yam physico-chemical parameters assessment and its bread sensory attributes." was carried out in the laboratory of INES-Ruhengeri for adding value to local yam called Dioscorea spp. The main objective was to assess physico-chemical parameters of fresh yam tubers and sensory attributes of produced bread from yam fermented flour. A sample size of $10 \mathrm{~kg}$ of each Dioscorea variety as fresh crude yam tubers was brought from Musanze market to INES laboratory for chemical analysis, fermentation and bread processing. Physico-chemical parameters analyzed in fresh crude yam tubers included moisture content, $\mathrm{pH}$, nutrient content and sensory evaluation of yam bread. The results showed that fresh crude yam tubers moisture content ranged from 75 to $77 \%$. This moisture content is favoring yam tubers spoilage and there is a need to process fresh yams into bread for adding value. The yielded fermented yam flour ranged from 18 to $20 \%$ from crude yam tubers. The dried and fermented yam flour moisture content was around $13 \%$ and met the standards, while $\mathrm{pH}$ was around neutral (from 6.66 to 6.72 ) leading to tubers deterioration. The flour had a dark-brown color from enzymatic browning occurring during fermentation process. According to Hedonic scale, the overall acceptability of yam breads was good with mean sensory scores ranging from 7.33 to 7.83 over 9 emitted by trained panelists. Fermented yam flour with Aspergillus niger and Aspergillus oryzae followed by Saccharomyces cerevisiae used in yam bread making was considered nutritious by panelists. Hence, the processed yam bread is a good source of nutrients including carbohydrates, protein, fat, minerals and probiotics. The use of fermented yam flour in bread making is advantageous due to increased nutritional value and reduced rate of staling. Adding value to fresh yam tubers can lead to income generation and enhanced shelf life of new developed yam bread. It is therefore recommended to promote yam cultivation and processing of tubers at industrial level for food security and sustainability.
\end{abstract}

Keywords: Attribute, bread, flour, moisture, nutrient, parameters, sensory and yam
Volume 8 Issue 6 - 2018

Francis Dominicus Nzabuheraheza, Anathalie Niyigena Nyiramugwera, Tombola M Gustave Department of Biotechnologies, Rwanda

Correspondence: Francis Dominicus Nzabuheraheza, Department of Biotechnologies, Faculty of Applied Fundamental Sciences (FAFS), Higher Institute of Education, Rwanda, Email nzabutd@yahoo.fr, nzabutdI@gmail.com

Received: March 16, 2018 | Published: November 23, 2018

\section{Introduction}

Yams are monocots, related to lilies and grasses. Native to Africa and Asia, yam tubers vary in size from that of a small potato to over $60 \mathrm{~kg}$ (130lb). Over 600 varieties of yams are known, and $95 \%$ of these crops are grown in Africa. ${ }^{1}$ The nutritional facts in fresh yam tubers are good for human consumption and animal feeding. ${ }^{2}$ Yam is the common name for some plant species in the genus Dioscorea (family Dioscoreaceae) that form edible tubers. Yams are perennial herbaceous vines cultivated for the consumption of their starchy tubers in Asia, Africa, Central and South America, and Oceania. The tubers themselves are also called "yams". There are many different cultivars of yams. Although some varieties of sweet potato (Ipomoea batatas) are also called "yam" in parts of the United States and Canada, the sweet potato is not part of the family Dioscoreaceae, but belongs in the unrelated morning glory family Convolvulaceae. ${ }^{3}$

Yam is one of the major starchy food crops having an edible tuber found in Rwanda. Yam is the common name for some species in the genus Dioscorea belonging to the family of Dioscoreacea. ${ }^{4}$ Yam is an important source of carbohydrate (starch) for Rwandan people after Irish potatoes, sweet potatoes, and cassava roots. Yam tuber is essentially a starchy food, its principal nutritional function being the supply of calories to the body. ${ }^{4}$ This characteristic contributes to the sustaining of food supply, especially in the scarcity periods at the start of the wet season (FAO, 1997). Dioscorea esculenta, commonly known as the Lesser Yam, is a yam species, but with a smaller corm than most other yams (Figure 1). ${ }^{5}$ Dioscorea alata, known as purple yam and many other names, is a species of yam, a tuberous root vegetable. The tubers are usually bright lavender in color, hence the common name, but they may sometimes be white (Figure 2) ${ }^{4}$ It is sometimes confused with taro and the Okinawa sweet potato (Ipomoea batatas cv. Ayamurasaki), although $D$. alata is also grown in Okinawa where it is known as beniimo. With its origins in the Asian tropics, D. alata has been known to humans since ancient times. Because it has become naturalized throughout tropical South America, Africa, Australia, the US southeast, $D$. alata has many different common names from these regions. The color of purple varieties is due to various anthocyan in pigments. The pigments are water-soluble, and have been proposed as possible food coloring agents Dioscorea rotundata, the white yam, and $D$. cayenensis, the yellow yam, are native to Africa. They are the most important cultivated yams. In the past, they were considered as two separate species, but most taxonomists now regard them as the same species. Over 200 varieties between them are cultivated (Figure $3){ }^{4}$ 


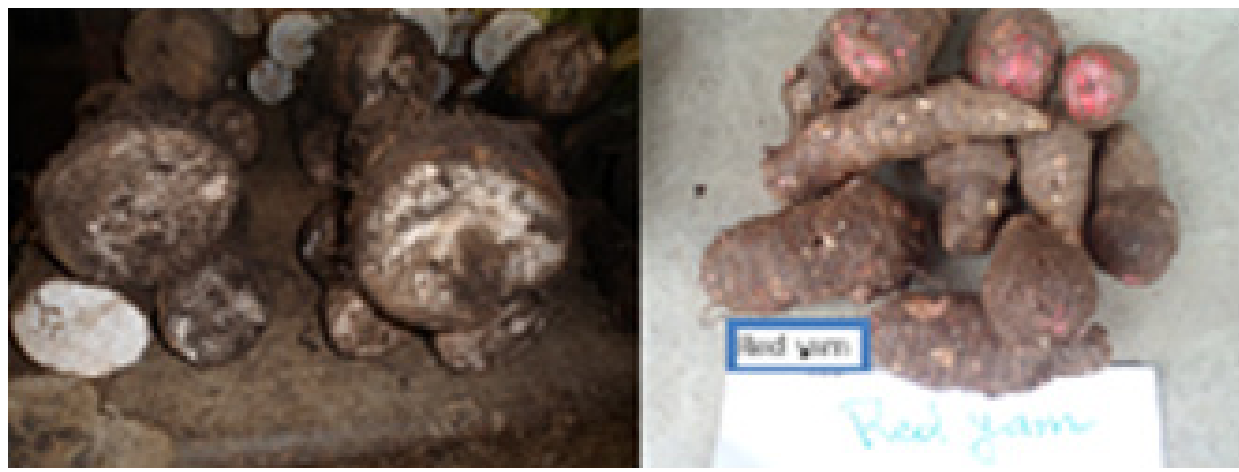

Figure I Tubers of Dioscorea esculenta.

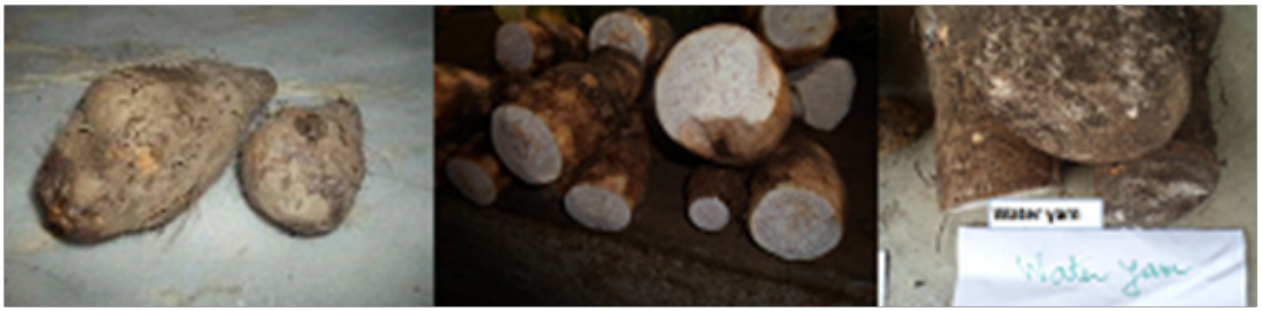

Figure 2 Tubers of water yam called Dioscorea alata.

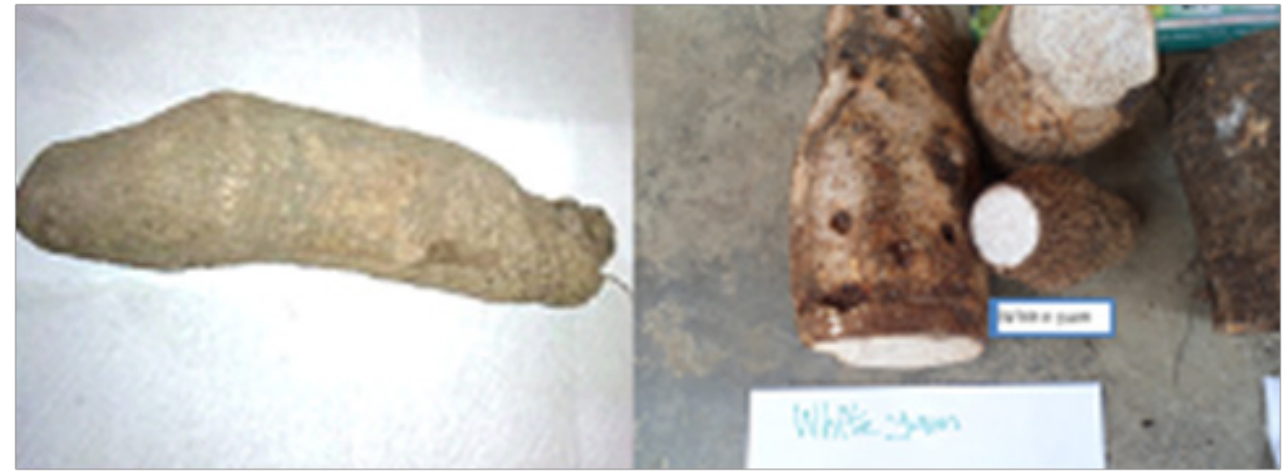

Figure 3 Tubers of Dioscorea rotundata.

White yam scientifically called Dioscorea rotundata or Dioscorea cayenensis (Dioscorea cayennensis subsp. Rotundata) is widely cultivated in Africa. It is one of the most important consumed yams. Yams are perishable and spoil rapidly in presence of pathogens, insects, rodents, and other pests found in soil and during storage. ${ }^{5}$ The flesh of yam species can be white, purple, and slightly dark while the processed flour color ranges from cream-white to dark brown. This discoloration phenomenon has long been studied in stored yam tubers and has mainly been associated with enzymatic browning due to the action of polyphenoloxidase. ${ }^{6}$ A major proportion of yam is eaten as boiled yam, roasted yam, fried yam, pounded yam and Amala which is stiff glutinous dough. The most processed traditional yam product is yam flour which contains protein carbohydrates and trace amounts of minerals and vitamins. ${ }^{6,7}$ Deterioration following the harvesting of fresh roots and tubers and the consequent losses are caused by mechanical damage, physiological changes within the plant, infections caused by decay organisms and pest infestation. ${ }^{7}$

There are many varieties of yam species widespread throughout the humid tropics, the most economically important species which are grown are white yam (D. rotundata), yellow yam (D. cayensis), water yam (D. alata), Chinese yam (D. esculenta) aerial yam ( $D$. bulbifera) and trifolate yam (D. dumentorum) ${ }^{6,8}$ The edible, matured yam does not contain any compounds however, bitter components tends to accumulate in immature tuber tissues of D. rotundata and
D. cayenesis. These are water-soluble alkaloids, which on ingestion produce severe and distressing symptoms. This yam phytochemical is poisonous and is boiled before use so that the alkaloid is leached from the tuber. ${ }^{5,8}$

The bitter compound of D. bulbifera (potato yam) induces a 3-furanosidenorditerpene called diosbulbin, which causes paralysis. Extract are used in immobilizing fish and in Malaysia, the yam is used in poisoning tigers and the extract is used in preparation of arrowpoison in Indonesia. Alkaloids dioscorine may be used as poison and steroids derivatives e.g. dysgenic is extracted for pharmaceutical use. $^{5}$ The processing of yam tuber is a long established practice, traditionally; yam is prepared in several ways for immediate consumption. Yam tubers are consumed in forms of chunks, flour, chips, fufu and slices, which are obtained from any of the processes of boiling, frying, drying, fermentation, milling, pounding, roasting and steaming. ${ }^{7}$ Raw yam flour has also found increasing use in bakery as dough conditioner in ice- cream and as thickener in soups. ${ }^{7}$ Yam can be processed into different forms for home use and commercial purpose. These include Boiled yam: yams are peeled, washed, sliced or cut into pieces of convenient sizes and boiled. The duration of boiling depends on the species and variety of the yam. Yam boiling without peeling conserves the vitamin content, where $95 \%$ of ascorbic acid is retained. Boiled yam is usually eaten with salted-sauce and spiced oil stew, meat or fish vegetable soup and, fried egg. Roasted 
yam: Whole or sliced yam is roasted on charcoal, oven-baked on hot ash or sand. In this research work, fermented yam flour is used to produce nutritious yam bread. ${ }^{3}$

\section{Materials and methods}

Representative samples of $10 \mathrm{~kg}$ of white yam (Dioscorea) tubers were purchased local traders of Musanze market in Rwanda and brought in sterile plastic containers to INES Laboratory for analysis and processing into yam bread. Yam tubers were sorted and washed with clean potable water to remove adhering soil and other undesirable foreign matters. The yams were hand-peeled using kitchen sharp knives (stainless steel) and sliced into sizes of $2 \mathrm{~cm}$ thickness. The slices of yam were parboiled in water at $50^{\circ} \mathrm{C}$ for 2 hours after which the yam was removed. The yam slices were fermented using selected pure starter culture of useful moulds. Yam flour was obtained by using sun dryers. Selected and identified molds (Aspergillus niger and Aspergillus oryzae) were used for sliced yam tubers fermentation and flour obtaining for further yam bread processing. Identification of moulds was done using microbiological procedures found in modern food microbiology.

Dried fermented yam slices were milled using locally fabricated hammer mill and used for pasta leavening with yeast and then yam bread making in oven. Sensory evaluation was done by panelists using hedonic scale over 9 scores. The production of yam flour process considered as flow chart is shown in below Figure 4. Figure 4 shows the flow chart of yam flour processing by sliced (chips) yam fermentation, drying and milling and sieving. ${ }^{2,3}$ This method is affordable by rural people. Molds are isolated from decaying yams and sweet potatoes. They are used for pure culture production in laboratory. ${ }^{8}$ The $\mathrm{pH}$ of fresh yam tubers was determined using hand $\mathrm{pH}$-meter Five grams of the flour sample was weighed into a beaker containing $25 \mathrm{ml}$ of distilled water. It is allowed to stand for 30 minutes with constant stirring. ${ }^{2,5}$

\begin{tabular}{|l|}
\hline \multicolumn{2}{|c|}{ Yam tubers sorting, washing and peeling } \\
\hline Yam Tubers Slicing (chips) and fermentation using selected molds \\
\hline
\end{tabular}

Sun-drying, milling/grinding, sieving, packaging, sealing, labeling, and storage

Dried and Fermented yam flour use for bread processing

Figure 4 Fermented yam flour production flow chart.

(Source:Author's design)

Yam flour is powdered starch widely used in food preparation. Typically white, the flour is commonly used in African dishes. ${ }^{1,5}$ It is prepared by grinding dried yams until they reach a powdered consistency. Dehydrated flour from yams may also be produced from sun drying. Yam is the common name for some species in the genus Dioscorea (family Dioscoreaceae). ${ }^{8}$ The economically important species grown are Dioscorea rotundata (white yam), Dioscorea alata (yellow yam), Dioscorea esculenta. ${ }^{6,8}$ In this study, fermented yam flours were produced using Aspergillus niger and Aspergillus oryzae for transformation of yam starch and inulin into maltose which is easy to be degraded by yeast (Saccharomyces cerevisiae widely used in bread fermentation). These molds used for degradation of yam polysaccharides are as follows: This Figure 5 shows the safe molds used in degradation of starch and inulin found in yam carbohydrates for facilitation of yeast attack of maltose. These both molds (Aspergillus niger and Aspergillus oryzae) were purely isolated and cultivated according to standards procedures. ${ }^{8}$ Fermented yam flour was obtained and used for further yam bread making.

The Figure 6 shows that fermented yam flour is obtained by washing fresh yam tubers, peeling, grating, fermenting, drying, granules milling, sieving the powder, bread making, properly packaging, labeling and sealing the final product. The flow chart of bread making is below presented in Figure 7: Bread has been baked for hundreds of years, and the same basic process is still used today. The main ingredients are flour, yeast, salt and water. The flowchart shows the processes used in an industrial bakery. If you baked bread at home, you would use similar principles but on a smaller scale. Concerning the sensory evaluation, the processed fermented yam flour was used for bread making and sensory attributes assessment by trained panelist. Hedonic scale (over 9 scores) test was used in measuring the sensory attributes intensity and acceptability of the processed bread. Thus, a 9-point hedonic scale was used to determine the overall acceptability of processed yam bread. Yam bread with $1=$ dislike extremely, $2=$ dislike very much, $3=$ dislike moderately, $4=$ dislike slightly, $5=$ neither like or dislike, $6=$ like slightly; $7=$ like moderately, $8=$ like very much and $9=$ like extremely. ${ }^{3,5}$

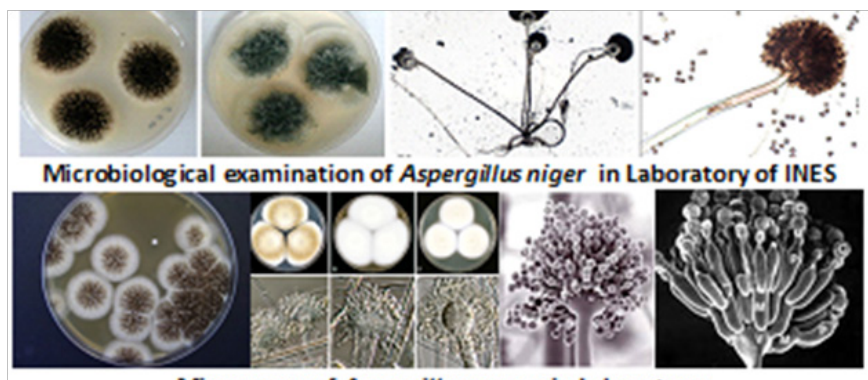

Micros copy of Aspergillus oryzae in Laboratory

Figure 5 Microbiological examination of Aspergillus spp. used in fermentation of yam flour.
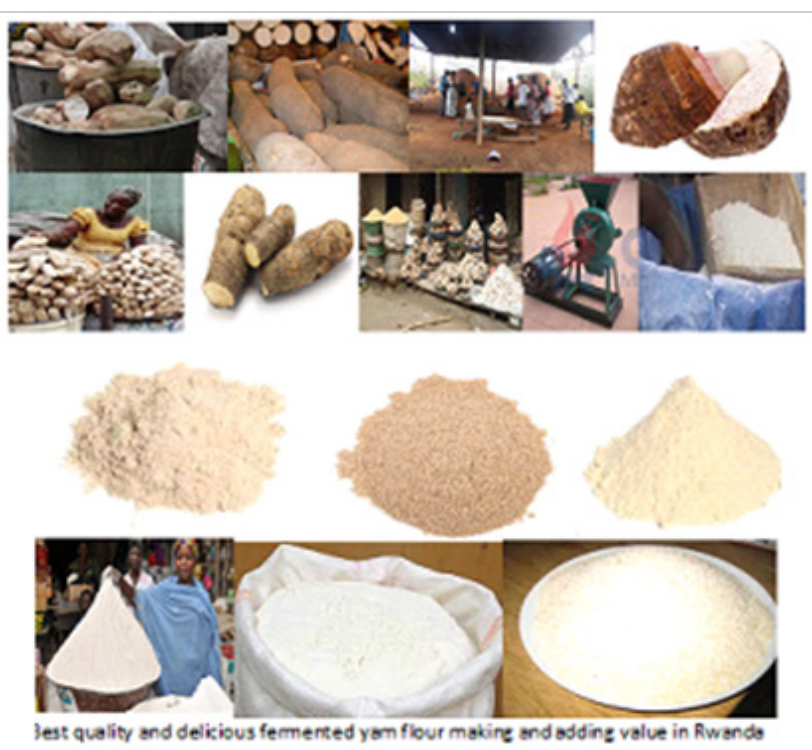

Figure 6 Making fermented yam flour. 


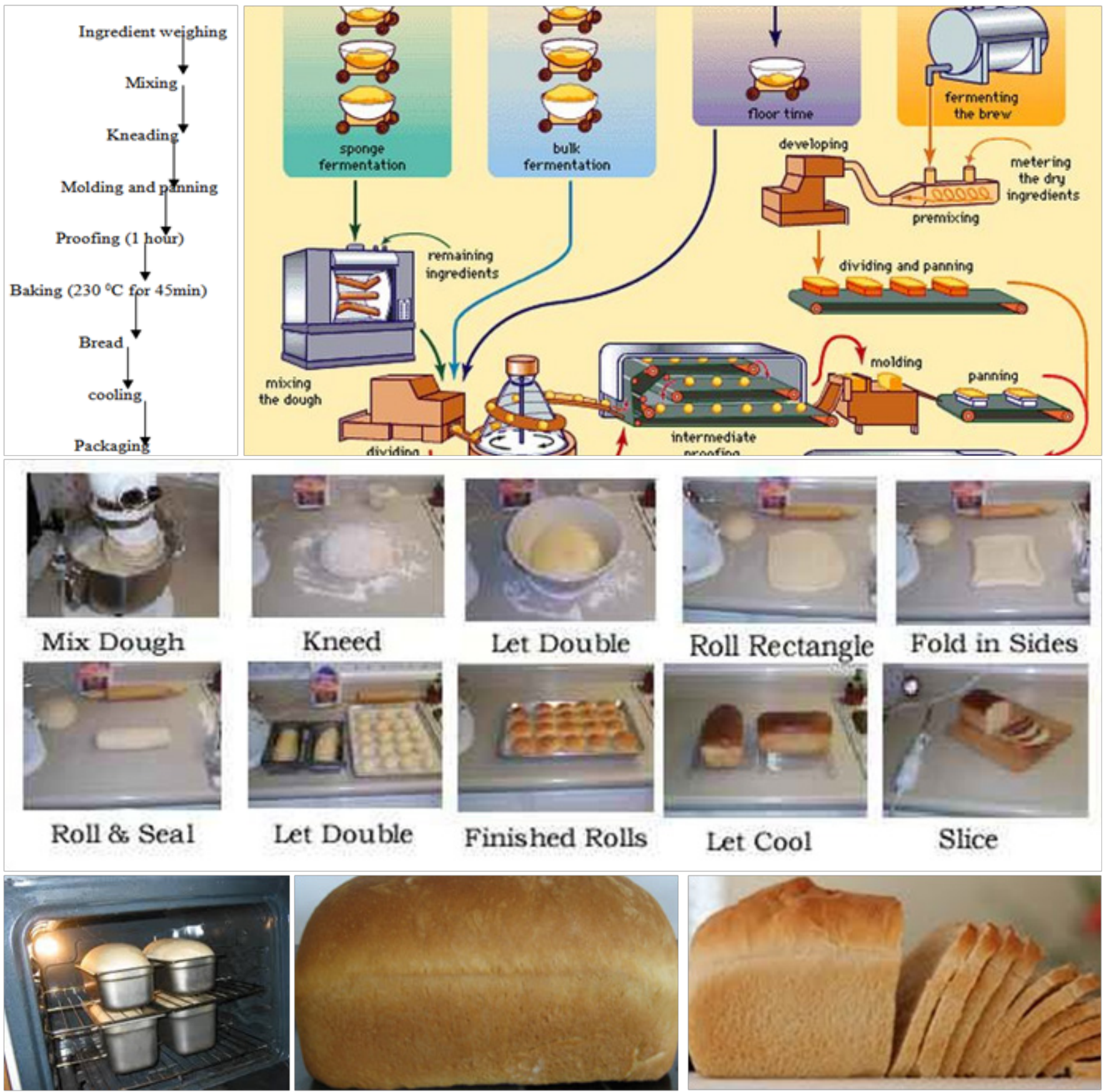

Figure 7 Bread making flow chart.

\section{Statistical analysis}

Data analysis was done using Microsoft Office Excel.

\section{Results and discussion}

The moisture content of fresh crude yam tubers ranged from $75.7 \%$ to $77.4 \%$. This moisture content can lead to rapid spoilage of tubers. Normally, tubers are perishable and there is a post-harvest loss. ${ }^{1,4}$ The $\mathrm{pH}$ ranges from 6.66 to 6.72 . This $\mathrm{pH}$ is slightly neutral that can lead to yam spoilage especially by mold that produce mycotoxins. ${ }^{1,3}$ Thus the $\mathrm{pH}$ of fresh crude yam tubers was around neutral which is one of the factors affecting microbial growth and spoilage of yam tubers. ${ }^{8}$ Both $\mathrm{pH}$ and moisture content favor multiplication of microorganisms in tubers. ${ }^{4,8}$ The brown color of processed yam flour and yam bread should be to enzymatic action during fermentation processes. ${ }^{1,3}$

This Figure 8 shows that the $\mathrm{pH}$ of all three samples of yam varieties was around neutral leading to rapid development of spoilage microorganisms. In fact this $\mathrm{pH}$ and moisture content can be better factors favoring microbial growth. ${ }^{1,4}$ The results of moisture content in fresh crude yam tubers are presented in below Figure 9.

According to Figure 9, crude yam tubers have moisture content ranging from 75 to $80 \%$ and the shelf-life should be enhanced by drying and flour making for better preservation and avoiding yam spoilage. ${ }^{1,7}$ In this case, the results of dry matter and nutrients content are presented in below Figure 10. 


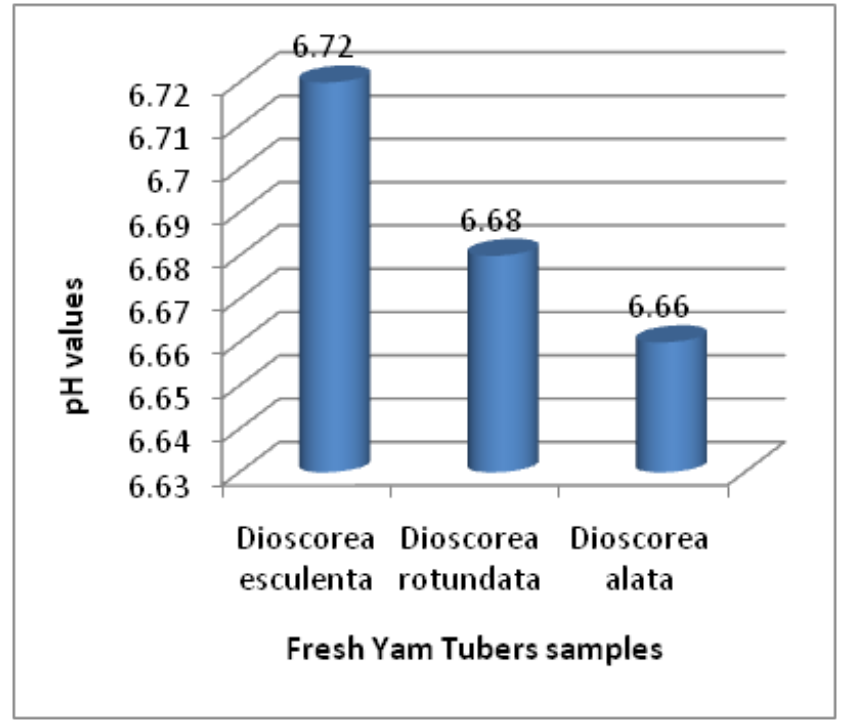

Figure 8 Determination of $\mathrm{pH}$ in crude yam tubers

According to Figure 10, the chemical composition of three yams shows a good content in starch and proteins that can allow making nutritious bread acceptable by consumers for fighting against malnutrition among people. These raw crude yams were washed, peeled, crushed, traditionally fermented and processed in order to obtain sun-dried fermented flours for further bread production. Root and tuber crops are second only in importance to cereals as a global source of carbohydrates. ${ }^{7}$ They also provide some minerals and essential vitamins, although a proportion of the minerals and vitamins may be lost during processing. ${ }^{3,5}$ Different alkaloids (diosbulbin, dioscorine, and diosgenin) found in fresh yam tubers were degraded by microorganisms used in pre-fermentation of sliced tubers and during yam flour processing. 5

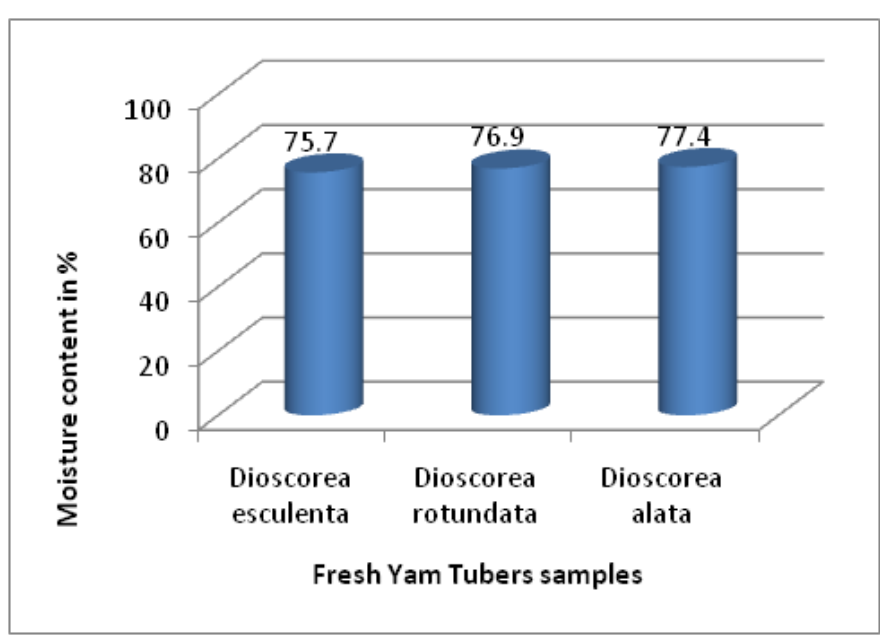

Figure 9 Determination of moisture content in fresh yam samples.

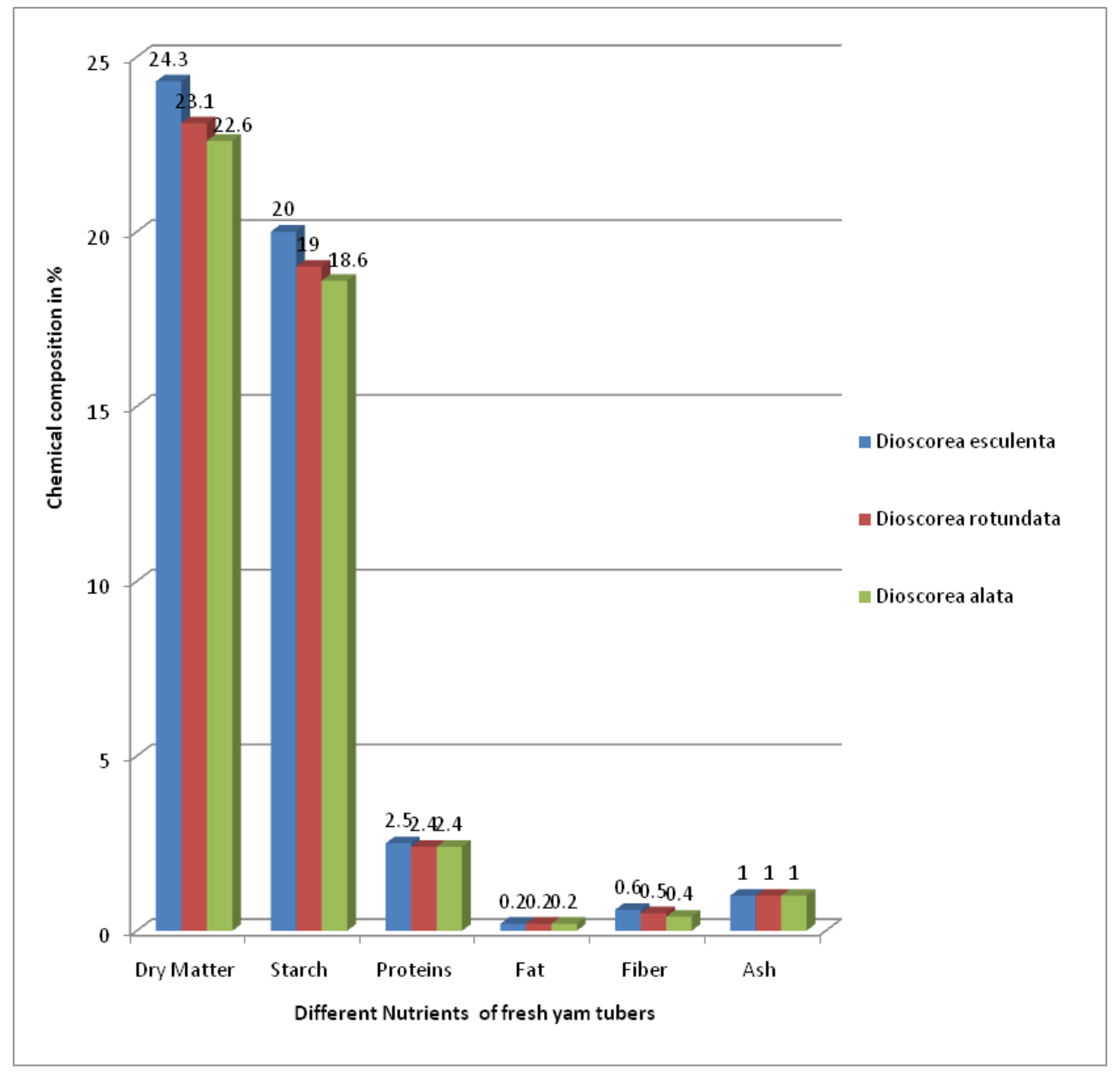

Figure 10 Nutritional values of raw fresh yams tubers found at Musanze market in Rwanda. 
This Figure 11 shows that the production of yam flour is ranging from 18 to $20 \%$ and the moisture content is around $13 \%$ that meets the standards. This yam flour can have a good shelf-life before bread processing. However it is better to process bread in fresh flour in order to prevent mold growth in rainy season. Bread is universally accepted as a very convenient form of nutritious food that is important to all populations for combating hunger especially in developing countries. Its origin dates back to the Neolithic era and is still one of the most consumed and acceptable staple food products in all parts of the world. It is a good source of nutrients, such as macronutrients (carbohydrates, protein, and fat) and micronutrients (ash or minerals and vitamins) that are essential for human health. ${ }^{7}$ However, the shelflife of yam flour depends on the additional measures taking at the time of packaging and the storage condition.

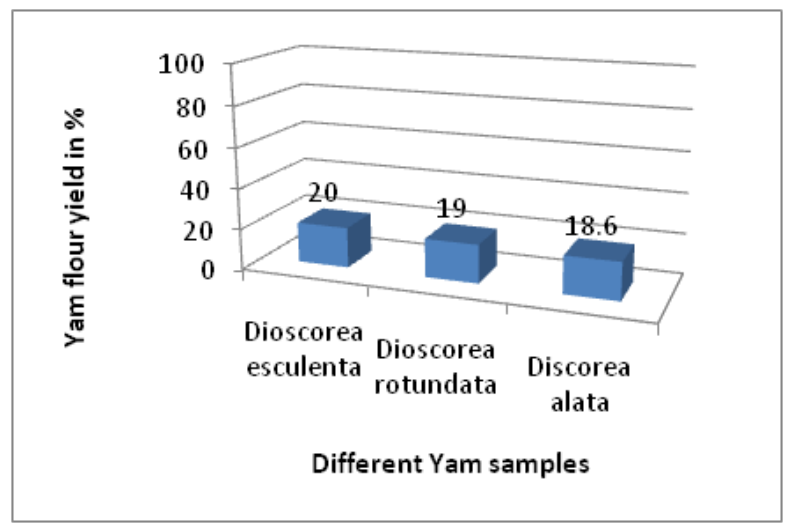

Figure II Dried yam flour production.

\section{Sensory evaluation of yam bread made in Rwanda}

According to 9score Hedonic scale, sensory evaluation was done in terms of organoleptic characteristics including color, aroma, taste and texture, and the results of overall acceptability are presented in below Figure 12. This Figure 12 shows that the overall acceptability of tested three kinds of fermented yam bread was very good with more than 7.3 over 9 according to Hedonic scale. The pre-fermented yam flour of three yam varieties produced good bread having a dark and brown color occurred during processing. ${ }^{5}$

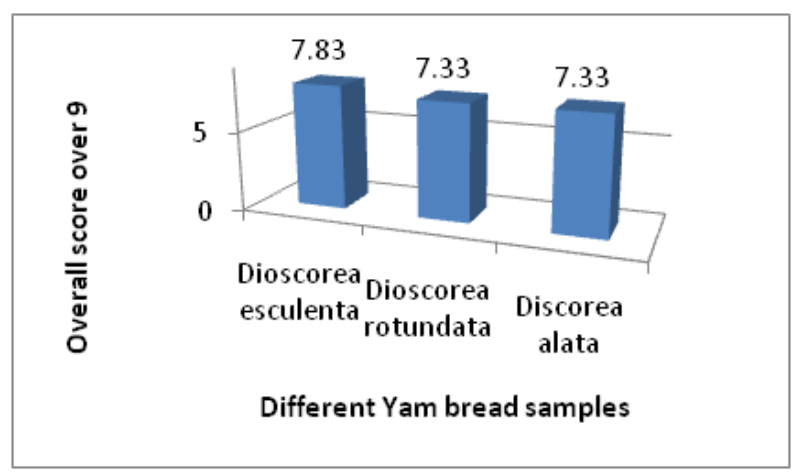

Figure 12 Sensory attributes of fermented yam bread.

\section{Conclusion}

Fermented yam flour allowed producing delicious and wonderful bread with good nutritional quality. The yam bread was appreciated by panelists. The study shows that the yam flour samples made in Rwanda were significantly different $(\mathrm{p}<0.05)$ in terms of the physical, functional and sensory properties of the collected samples. The sieve analyses showed that the yam flour sold in the market were prefermented and this affect the percentage of brownness of the yam flour, this could increase the brown color of fermented yam flour. This yam bread made in Rwanda had good scores in terms of overall acceptability of sensory attributes. Nutrients like amino-acids, pre biotics, pro biotics, minerals and vitamins produced from fermentation process are available and ready to be absorbed in intestinal tract once yam bread is consumed. Also alkaloids found in yams were degraded by used molds and yeast during fermentation and drying. Further studies should be carried out on microbial analysis and storage stability of the yam flour and yam bread shelf-life. It is also recommended that yam flour fermented is nutritious food for combating malnutrition in developing countries. Yam flour should be protected from my co toxins that can generate cancer among consumers and animals. Regulatory agency like Rwanda Standards Board (RSB) is paying more attention to locally processed food products.

\section{Acknowledgments}

None.

\section{Conflicts of interest}

The authors declare that there is no conflicts of interest.

\section{References}

1. Andreas BY. Controlling post harvest loss of yam (Dioscorea spp) by Application of Gibberlic acid (GA). London: Macmillan Publishers limited; 2003:68-72.

2. AOAC Official Methods of Analysis. 30th ed. Washington DC: Association of Official Analytical Chemists; 2000:19-36.

3. Brunschwetier J. Structure and Texture of yam (Dioscorea spp) and processed yam product. London: Macmillan Publishers limited; 2004:112-115.

4. Coursey DG. Yams: Tropical Agricultural Series. London: Longman Group Ltd; 1967:256-257.

5. Emiola L, Delrosa LC. Physiochemical characteristics of Yam Starches. Journal of Food Biochemistry. 1981;5:115-130.

6. Harrigan WF, ME McCance. Laboratory methods in Food and Dairy Microbiology. New York: Academic press; 1967:351-354.

7. Iwuoha CI. Comparative evaluation of the physio-chemical characteristics of flours from steeped tubers of white yam (Dioscorea rotundata poir), and Water yam (Dioscorea alata $L$ ) and yellow yam (Dioscorea cayensis Lam). Tropicultura. 2004;22(2):56-63.

8. Jay MJ. Modern Food Microbiology. 5th ed. London: Champion and Hall; 1991:38-52. 